\title{
Climatic and oceanic associations with daily rainfall extremes over southern Africa
}

Article

Published Version

Williams, C. J. R., Kniveton, D. and Layberry, R. (2007)

Climatic and oceanic associations with daily rainfall extremes over southern Africa. International Journal of Climatology, 27 (1). pp. 93-108. ISSN 0899-8418 doi: https://doi.org/10.1002/joc.1376 Available at https://centaur.reading.ac.uk/19281/

It is advisable to refer to the publisher's version if you intend to cite from the work. See Guidance on citing.

To link to this article DOI: http://dx.doi.org/10.1002/joc.1376

Publisher: John Wiley \& Sons

All outputs in CentAUR are protected by Intellectual Property Rights law, including copyright law. Copyright and IPR is retained by the creators or other copyright holders. Terms and conditions for use of this material are defined in the End User Agreement.

\section{www.reading.ac.uk/centaur}

\section{CentAUR}

Central Archive at the University of Reading 
Reading's research outputs online 


\title{
Climatic and oceanic associations with daily rainfall extremes over southern Africa
}

\author{
C. J. R. Williams, ${ }^{\mathrm{a}, *}$ D. R. Kniveton ${ }^{\mathrm{a}}$ and R. Layberry ${ }^{\mathrm{b}}$ \\ a Department of Geography, University of Sussex, $U K$ \\ b Environmental Change Institute, University of Oxford, UK
}

\begin{abstract}
:
Changes in climate variability and, in particular, changes in extreme climate events are likely to be of far more significance for environmentally vulnerable regions than changes in the mean state. It is generally accepted that sea-surface temperatures (SSTs) play an important role in modulating rainfall variability. Consequently, SSTs can be prescribed in global and regional climate modelling in order to study the physical mechanisms behind rainfall and its extremes. Using a satellite-based daily rainfall historical data set, this paper describes the main patterns of rainfall variability over southern Africa, identifies the dates when extreme rainfall occurs within these patterns, and shows the effect of resolution in trying to identify the location and intensity of SST anomalies associated with these extremes in the Atlantic and southwest Indian Ocean. Derived from a Principal Component Analysis (PCA), the results also suggest that, for the spatial pattern accounting for the highest amount of variability, extremes extracted at a higher spatial resolution do give a clearer indication regarding the location and intensity of anomalous SST regions. As the amount of variability explained by each spatial pattern defined by the PCA decreases, it would appear that extremes extracted at a lower resolution give a clearer indication of anomalous SST regions. Copyright (C) 2006 Royal Meteorological Society
\end{abstract}

KEY WORDS rainfall; variability; extremes; SST; PCA; southern Africa

Received 14 November 2005; Revised 5 May 2006; Accepted 16 May 2006

\section{INTRODUCTION}

It is becoming increasingly accepted that any potential climate change will not only have an influence on mean climate but also significantly alter climatic variability (Tegart et al., 1990). This may lead to a change in the frequency of extreme events. This latter change will have important impacts, such as flooding and drought, on human and natural systems (McGuffie et al., 1999). Changes in rainfall extremes have proved especially problematic for environmentally and socio-economically vulnerable regions, such as southern Africa, which already experience a highly variable climate (Hudson and Jones, 2002).

Although the importance of accurate information on rainfall is undisputed, a continuing problem in southern Africa is the lack of rainfall data owing to a range of factors, including technological and scientific underdevelopment exacerbated by civil war, extensive poverty, and political instability (Desanker and Magadza, 2001). Hence, the past studies on daily rainfall variability have largely been restricted to the relatively data-rich South Africa (Fauchereau et al., 2003). As can be seen in

* Correspondence to: C. J. R. Williams, Department of Geography, University of Sussex, Falmer, Brighton BN1 9QJ, UK.

E-mail: C.J.R.Williams@sussex.ac.uk
Figure 1(a), daily reports from the Global Telecommunications System (GTS) from 1948 to 2001 show a concentration of rain gauges in South Africa, but with few or no measurements in large areas elsewhere, especially in countries to the west, such as Angola. Satellitederived rainfall data, providing near uniform coverage over Africa, are a possible solution to this problem.

Research on the large-scale associations with rainfall variability has previously concentrated on seasonal and annual rainfall using coarse spatial resolution precipitation data (e.g. Nicholson, 1986; Ropelewski and Halpert, 1987; Lindesay, 1988; Mason and Tyson, 1992; Moron et al., 1995; Rocha and Simmonds, 1997; Goddard and Graham, 1999). Many of these studies have suggested the importance of SST in modulating rainfall variability, either indirectly such as an alteration in the position of the ITCZ (Biasutti et al., 2004) or by more direct 'local' mechanisms (e.g. Janowiak, 1988; Walker, 1990; Jury and Pathack, 1993; Jury et al., 1993; Mason, 1995; Shinoda and Kawamura, 1996; Reason and Lutjeharms, 1998b). As an example of the latter, Reason and Keibel (2004) argue that the unusual behaviour of the Tropical Cyclone Eline was partly caused by anomalous SST in the Indian Ocean. To date, work on investigating the influence of SST on rainfall variability over southern Africa has focused on three ocean basins. Firstly, the Pacific, which has remote influences such as those impacting on 
(a)

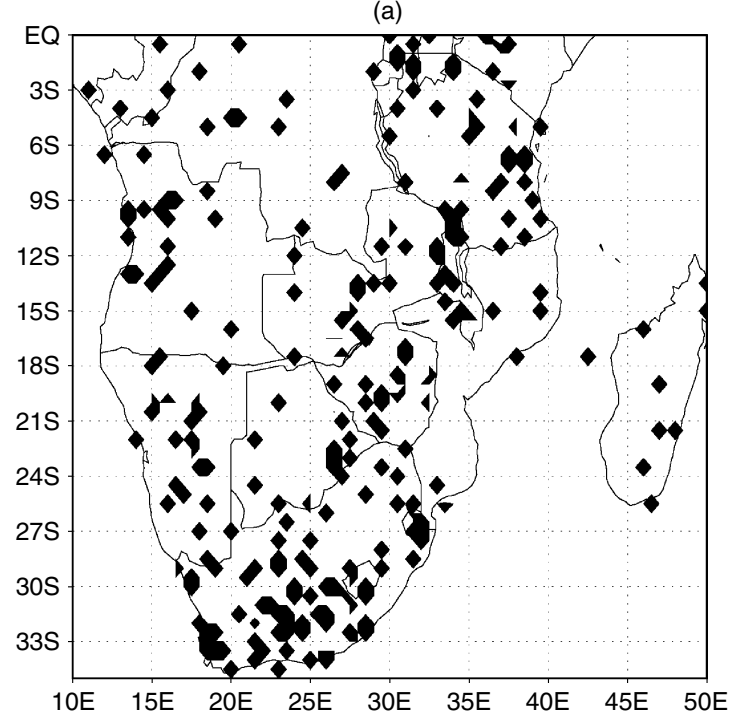

(b)

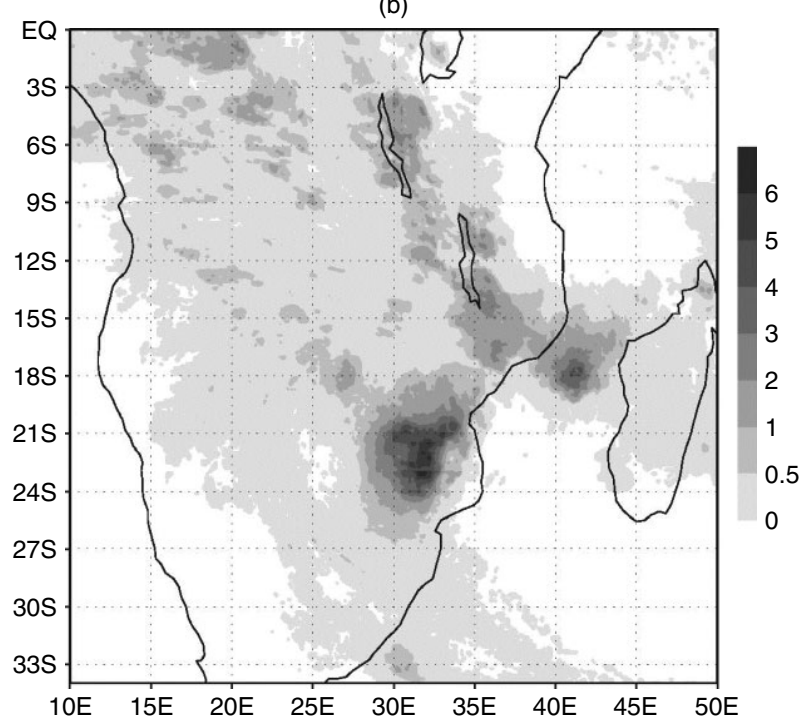

Figure 1. (a) Average spatial distribution of daily reports from the GTS network, 1948-2001. Black areas show regions with an average of one or more GTS station. (b) Estimated mean rainfall from MIRA for a high rainfall event for 21-25 February 2000. Rainfall in $\mathrm{mm} \mathrm{h}^{-1}$.

the frequency of dry spells over South Africa (Reason et al., 2005b). Secondly, the Indian Ocean, which can have remote and local influences (on primarily the eastern side of the subcontinent), such as when warm (cool) SST anomalies in the southwest (southeast) Indian Ocean results in increased rainfall over southeastern Africa (Suzuki et al., 2004). Thirdly, the South Atlantic, which primarily affects the western side of southern Africa and can cause high rainfall over southwest South Africa when the SST anomaly is warm (cool) in the southwest and southeast (central) South Atlantic (Reason and Jagadheesha, 2005a).

In addition to identifying SST patterns associated with rainfall variability, idealised SST anomalies have been used to force global and regional general circulation models to simulate rainfall variability over various regions, such as the Sahel (Moron et al., 2003), northwest
Africa (Li et al., 2003), Africa as a whole (Paeth and Friederichs, 2004), and southern Africa (Reason and Godfred-Spenning, 1998a; Reason, 1998; Rautenbach and Smith, 2001; Reason, 2002; Misra, 2003). However, while much attention has focused on seasonal and annual rainfall totals, little research has been carried out on daily extreme rainfall. In part, this has been because of a dearth of high spatial and temporal resolution data. The identification of rainfall variability is a function of scale, with the ability to highlight rainfall extremes increasing with higher spatial and temporal resolutions (i.e. data at a coarse scale are less likely to show extreme events than if a higher resolution is used). Thus, in this study we pursue the dual aims of trying to identify possible climatic and oceanic associations with daily extremes over southern Africa, while examining the effect of the spatial resolution of the rainfall data (used to denote the extreme events) in clearly defining the relevant regions of related SSTs. The issue of the spatial resolution of the data set is an important one, as obtaining rainfall data at increasingly higher resolutions is expensive and often logistically difficult from in situ measurements. An alternative is to use current remote sensing data in which the field of view and pixel sizes of the relevant data are of the order of $25-625 \mathrm{~km}^{2}$.

Before discussing some of the possible mechanisms linking the atmospheric circulation patterns with SST, this section briefly describes the main rain-producing systems at the synoptic-scale over southern Africa. In Section 3 we describe the data and methodologies used, in Sections 4 and 5 the patterns of variability and the possible atmospheric and oceanic associations with the extreme events within these patterns are explored at two spatial resolutions. Section 6 discusses the results of the study.

\section{ATMOSPHERIC AND OCEANIC LINKS}

\subsection{Atmospheric circulation systems}

The dominant systems for most of southern Africa are the tropical temperate trough (TTT) features, which generally form a cloud-band and related convection with a NW-SE orientation across the subcontinent. These features have been identified as the leading mode of variability on the monthly timescale for most months during the wet season (Washington and Todd, 1999; Todd et al., 2004). The troughs are influenced by the position of a semipermanent surface-low that is located over southern Africa, such that the cloud-band (and rainfall) occurs over southern Africa when the low is situated over the Namibian-Angolan border (Harrison, 1984; Tyson, 1986; Mulenga, 1998). When this occurs, low-level flow is likely to be easterly over subtropical southern Africa drawing in moisture from the southwest Indian Ocean; at the same time, anomalously strong westerlies to the north of the surface-low draw in moisture from the tropical South Atlantic and, in response to convergence from these two flows, widespread summer rainfall occurs 
across southern Africa (Reason, 1998). The upper branch of a Walker type circulation over the South Atlantic and southern Africa is formed by the easterly return flow aloft (Reason, 1998). Conversely, when the low is situated further to the east over Mozambique, southern Africa is likely to be drier, because the cloud-band, low-level convergence, and rainfall occur more over Madagascar; this situation also results in a reversal of the Walker type circulation over the South Atlantic and southern Africa with low-level easterly and westerly flows aloft, and relative subsidence over western and central southern Africa (Reason, 1998).

\subsection{Possible mechanisms linking atmospheric circulation with SST}

A South Atlantic or Indian Ocean SST anomaly may influence southern African rainfall, both locally (i.e. near to the anomaly) and remotely; the local effect on rainfall may be via modulations to the latent heat flux causing changes in the moisture levels being drawn into southern Africa, and the remote effect may be caused by a shift in the location of the TTT features (Reason, 1998).

A possible mechanism for this local impact on rainfall, which mainly affects the coastal regions of southern Africa, is from the direct impacts on temperature and pressure gradients, which cause an alteration in the regional moisture flows (Hirst and Hastenrath, 1983; D'Abreton and Lindesay, 1993). A possible mechanism for the larger-scale remote impact on rainfall is that SST variability in the Agulhas Current influences the surface moisture fluxes into the boundary layer, which are strongly associated with the atmospheric circulation and can either promote or suppress favourable conditions for the creation and survival of TTTs (Mey et al., 1990; Jury, 1994; Reason, 1998).

\section{DATA AND METHOD}

\subsection{Rainfall data}

There is a lack of high spatial and temporal resolution data over southern Africa. Remote sensing and the availability of satellite-derived data provide an opportunity to resolve this problem (Todd et al., 2001); however, it is recognized that these data have uncertainties due to the indirect relationship between the remotely sensed measurements and precipitation.

The high-resolution data used in this study were obtained using the Microwave Infrared Algorithm (MIRA), which consists of an infrared (IR) brightness temperature/rain rate relationship, variable in space and time, that is derived from coincident observations of IR brightness temperature data and Special Sensor Microwave Imager (SSM/I) MW rain rates. Rainfall data from this data set are available from 1993 to 2002 at a $0.1^{\circ}$ latitude/longitude resolution and cover the southern African region of $0^{\circ}-35^{\circ} \mathrm{S}$ and $10^{\circ}-50^{\circ} \mathrm{E}$. An example of the estimated mean rainfall from MIRA can be seen in Figure 1(b), which shows the extreme rainfall event of 21-25 February 2000 and which was associated with the Tropical Cyclone Eline (Layberry et al., 2006). Validation results suggest that the MIRA data set compares more favourably with GTS measurements than other satellite-based rainfall algorithms (Layberry et al., 2006), such as the normalized GOES Precipitation Index (GPI) (Arkin and Meisner, 1987).

\subsection{Principal component analysis (PCA)}

One of the reasons for carrying out a PCA on rainfall data is to identify and differentiate between the most common patterns of spatial variability within a given data set and separate the different patterns of variability into individual components. Thus, the leading principal component or mode will explain the pattern of rainfall that accounts for the highest amount of variability, and the amount of variability explained by each mode decreases as the principal component number increases. It should be stressed that a PCA produces patterns of rainfall variability rather than patterns of actual rainfall, as the data are normalized before the procedure is carried out and any sense of the mean rainfall is removed. The PCA is used in this work, firstly, to identify the main patterns of daily rainfall variability and, secondly, to highlight extreme rainfall events within each pattern and associations with atmospheric circulation and SST. The assumption here is that extreme events are arranged in the same pattern as the mode of variability within which they are found; while this is a logical assumption, its validity is discussed later.

The data were first smoothed and normalized to remove any seasonal cycle before being subjected to a PCA with space as the variables and time as the observations (Richman, 1986; Joliffe, 1987; White et al., 1991). Two smoothing distances were used for the PCA. Firstly, a smoothing distance of 25 grid cells giving a spatial resolution of $2.5^{\circ}$ and, secondly, a smoothing distance of 10 grid cells giving a higher spatial resolution of $1^{\circ}$. Thus, patterns of spatial variability were obtained at two spatial scales, hereafter referred to as lower and higher resolutions, respectively.

The first three Empirical Orthogonal Functions (EOFs, representing the spatial extent of each mode of variability) and corresponding Principal Components (PCs or amplitudes, representing the temporal evolution of each EOF) were retained for the wet season from November to April as a whole (hereafter referred to as the wet season). The resulting EOFs cover the region $5-35^{\circ} \mathrm{S}$ and $10-47.5^{\circ} \mathrm{E}$. It was necessary to undertake the PCA on a seasonal timescale, as opposed to, for example, monthly, because the number of observations must always be greater than the number of variables. Consequently, in order to analyse at a $1^{\circ}$ spatial resolution it was necessary to increase the period to cover the whole wet season.

The North Test was used to determine the stability of each EOF (North et al., 1982). As can be seen in Table I, all three EOFs pass the North Test at both spatial resolutions and so may be trusted to be stable. 
Further, taking the PCA with lower spatial resolution as an example, all subsequent patterns pass the test until the twelfth EOF, by which time the percentage of total variance accounted for by that EOF drops to $1.83 \%$ (not shown). The first three patterns were retained for this study because the percentage of total variance falls to below 3\% (4\%) in the fourth EOF using the higher (lower) spatial resolution.

A documented problem with using unrotated EOFs is that the first EOF may often produce a centred monopole pattern of large, uniformly positive loadings (Buell, 1975). A possible solution to this is rotation of the resulting EOFs (Richman, 1986). However, in this study it is argued that the leading unrotated EOF emerged as a pattern other than a monopole; consequently, as in the work by Washington and Todd (1999), it is assumed that the unrotated EOFs have a physical meaning and further rotation is not required.

\subsection{Composite analysis}

Extreme events were obtained from the time series of amplitudes from each EOF at the two spatial resolutions where an extreme event is defined as any peak in variability that is greater than or equal to two standard deviations of that principal component. The dates corresponding to the extreme events were extracted from the time series, creating a list of days during the 10 -year period. These dates were then used as a basis for composite analysis using the on-line tools from The NCEP/NCAR 40-year Reanalysis Project at the NOAA-CIRES Climate Diagnostics Center (Kalnay et al., 1996). The variables used in this study were surface precipitation (in $\mathrm{mm} \mathrm{day}^{-1}$ ), geopotential height (in metres) at a vertical level of $850 \mathrm{mb}$, and surface temperature $\left(\mathrm{in}^{\circ} \mathrm{C}\right)$. The composite mean, obtained by subtracting the extreme negative dates from the extreme positive dates, is used. The two spatial resolutions were compared by subtracting the lowresolution composites from the high-resolution composites. The composites and difference plots cover the region $3-33^{\circ} \mathrm{S}$ and $10-47.5^{\circ} \mathrm{E}$, with some larger projections to cover all of Africa and the surrounding oceans.

\section{VARIABILITY AND ASSOCIATIONS: LOW RESOLUTION}

\subsection{Patterns of variability at $2.5^{\circ}$ spatial resolution,} extreme days and associations

4.1.1. EOF 1. As shown in Figure 2, the leading EOF for the wet season displays a pattern of positive loadings over the far eastern South Atlantic and negative loadings in the northeast and central parts of the subcontinent. When compared with Figure 3, showing the precipitation composite of positive minus negative extreme amplitudes from the first EOF, there is good agreement between the region of low rainfall and the region of negative loadings (Figure 2) over eastern and central southern Africa. This agreement supports the hypothesis that the extremes are arranged in a similar way to the average rainfall patterns. The smaller regions of positive loadings are highlighted as high rainfall in the composite mean, particularly over Angola and off the Tanzanian coast. The positive loadings from the first EOF over the southeastern Atlantic and Namibia are not as coherent in Figure 3, this is because a rainfall amount of between $2-5 \mathrm{~mm} \mathrm{day}^{-1}$ is high for this region but lower than the rainfall in Angola and Tanzania. Both these regions of positive loadings, and the larger region of negative loadings, are shown as statistically significant at the $90 \%$ significance level.

Inspection of the near-surface geopotential height composite over southern Africa (Figure 4), associated with the extreme rainfall dates, shows a ridge of relatively high-pressure extending inland as far as Zimbabwe. This may be associated with the quasi-stationary standing waves, in particular, wave numbers 1 and 3, which are particularly important for the southern African climate (Tyson and Preston-Whyte, 2000; Hudson and Jones, 2002) as they can influence the patterns of upper level (surface) divergence (convergence). Smaller regions of low pressure are also shown in equatorial southern Africa. If the surface-temperature structures (again from the composite of positive minus negative extreme amplitudes from the first EOF) are examined (Figure 5), three regions of warm anomalies are evident: a widespread region in the central southern Atlantic, a small but strong region over Angola, and a weaker region in the equatorial Indian Ocean. There is also a band of cold anomalies extending through both oceans between approximately $30-35^{\circ} \mathrm{S}$, and throughout the subcontinent. All of these regions of warm anomalies, as well as the band of cold anomalies, are shown to be statistically significant at the $90 \%$ level; further, the warm anomalies are also significant at the $95 \%$ level (not shown).

This distribution of rainfall variability may be associated with an Atlantic El Nino pattern (Merle, 1980; Binet et al., 2001). Under normal conditions, two Walker-style cells that are reverse to each other are thought to operate over southern Africa, with rising air and convection occurring over eastern southern Africa and subsidence

Table I. Monthly variance (\%) explained by each EOF and results of North Test (North et al., 1982). $1=$ pass, $0=$ fail.

\begin{tabular}{|c|c|c|c|c|c|c|}
\hline \multirow[t]{2}{*}{ Month } & \multicolumn{2}{|c|}{ EOF 1} & \multicolumn{2}{|c|}{ EOF 2} & \multicolumn{2}{|c|}{ EOF 3} \\
\hline & Variance & North & Variance & North & Variance & North \\
\hline Nov-Apr $\left(2.5^{\circ}\right)$ & 9.60 & 1 & 5.22 & 1 & 4.45 & 1 \\
\hline Nov-Apr $\left(1^{\circ}\right)$ & 7.58 & 1 & 3.79 & 1 & 3.26 & 1 \\
\hline
\end{tabular}




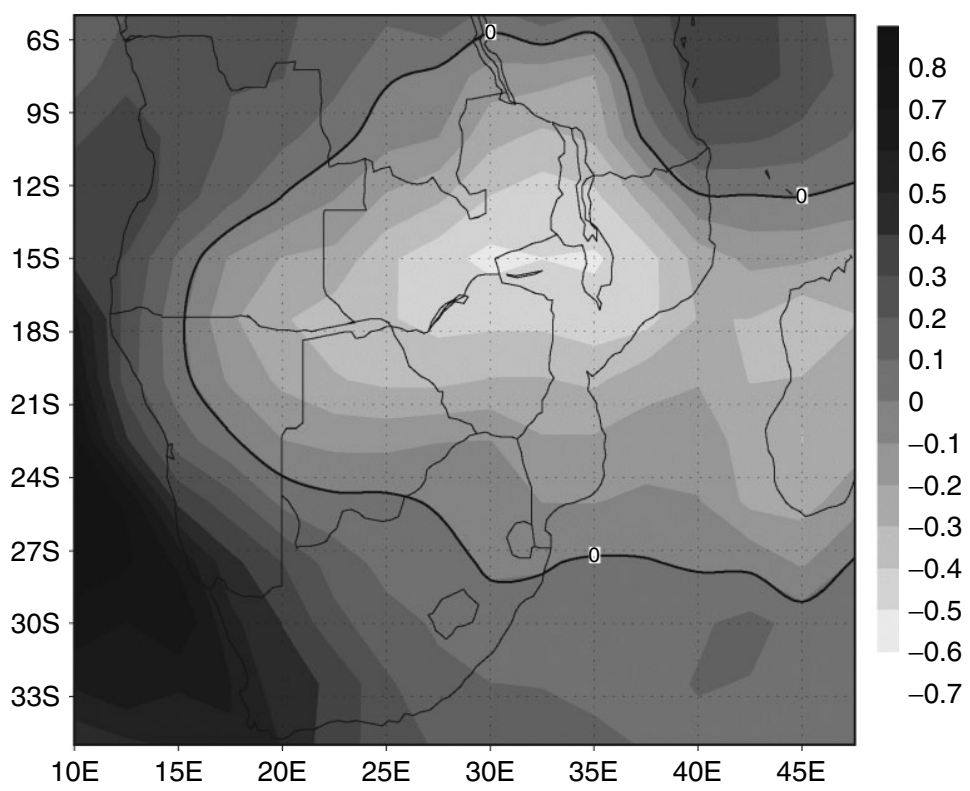

Figure 2. Spatial pattern of amplitudes from EOF 1 at $2.5^{\circ}$ spatial resolution, showing Nov-Apr rainfall variability. Solid line $=$ zero contour.

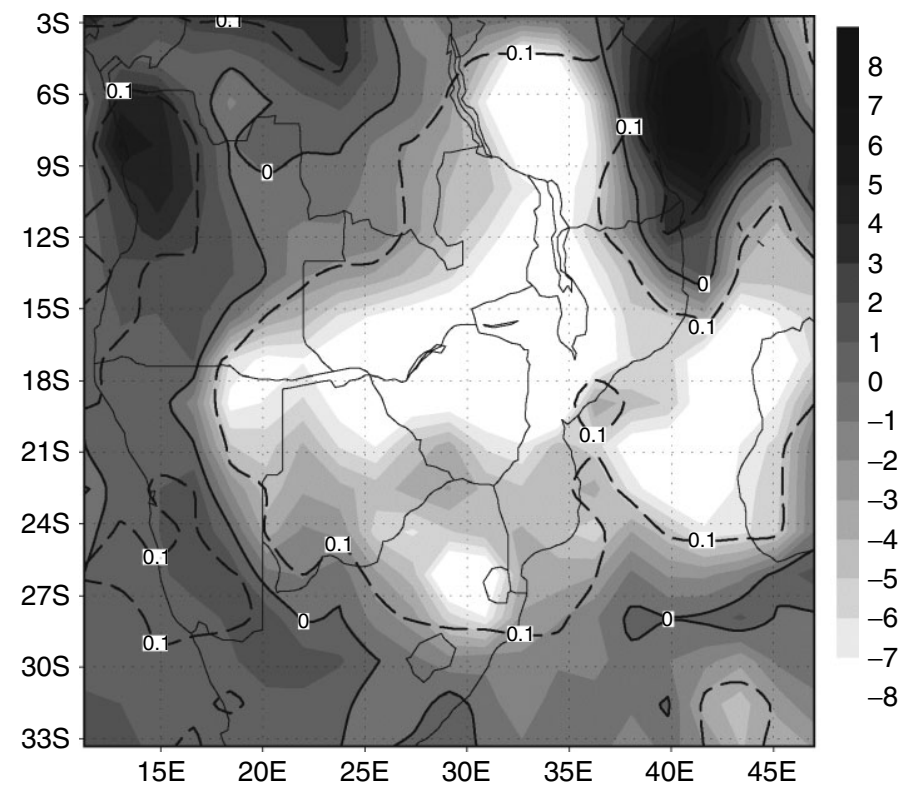

Figure 3. Surface precipitation composite mean (pos-neg amplitudes) from EOF 1 at $2.5^{\circ}$ spatial resolution. Precipitation in mm day ${ }^{-1}$. Solid line $=$ zero contour, dashed line $=0.1$ significance level.

occurring over a cold South Atlantic (Tyson, 1986). In this situation the TTTs are positioned to the east of southern Africa, resulting in a wet eastern and dry western subcontinent. However, the surface-temperature composite corresponding to extremes arranged in the leading mode of rainfall variability shows warm anomalies in the central South Atlantic. This may have the effect of suppressing the Atlantic Walker cell and instead being favourable for the creation of a Hadley-style circulation, enhancing the region of low pressure over equatorial southern Africa, as seen in Figure 4. This would draw the low-latitude component of the TTTs to the west of the subcontinent where they would be anchored by the equatorial low pressure and would diagonally cross western southern Africa.
4.1.2. EOF 2. The loadings forming the second EOF are shifted to the east, relative to the first, and are orientated into two NW/SE diagonal bands (Figure 6). Here, the positive loadings are centred over Zimbabwe and form a diagonal pattern reaching down across Swaziland and into the southwest Indian Ocean. The negative loadings, again orientated in a similar NW/SE diagonal pattern, are now centred to the east of Lake Nyasa rather than over Zambia as in the first EOF. The precipitation composite of extreme amplitudes, Figure 7, replicates to some extent the same pattern of variability as that seen in this EOF, again supporting the hypothesis that the common and extreme patterns of rainfall are arranged similarly. This composite shows the region of highest rainfall over eastern and central southern Africa, with a 


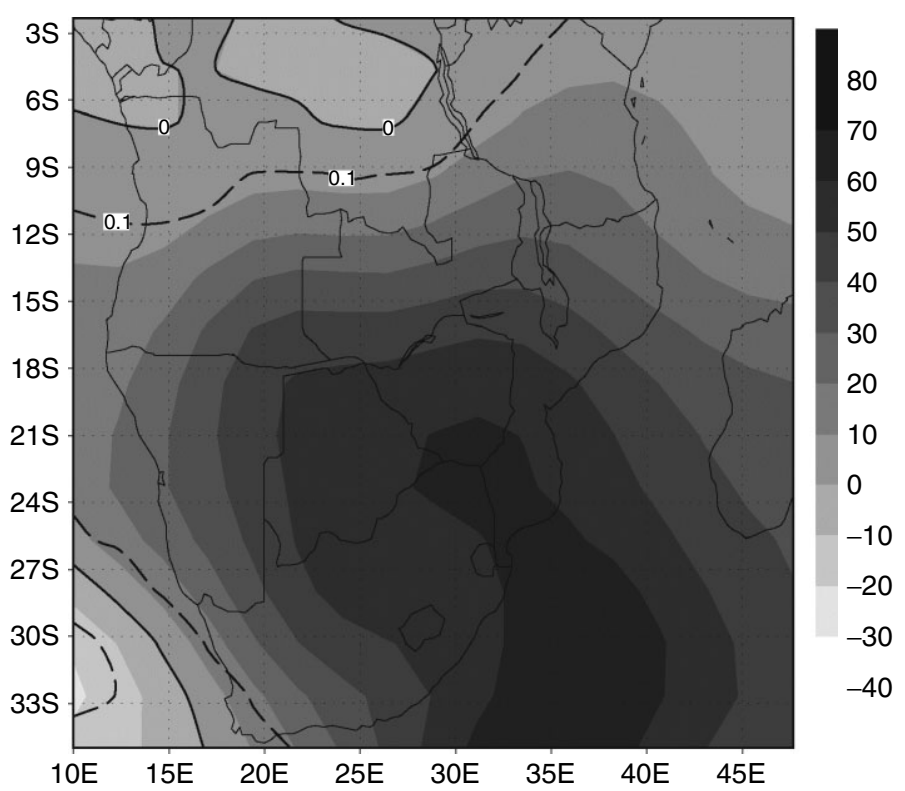

Figure 4. $850 \mathrm{mb}$ geopotential height composite mean (pos-neg amplitudes) from EOF 1 at $2.5^{\circ}$ spatial resolution. Heights in metres. Solid line $=$ zero contour, dashed line $=0.1$ significance level.

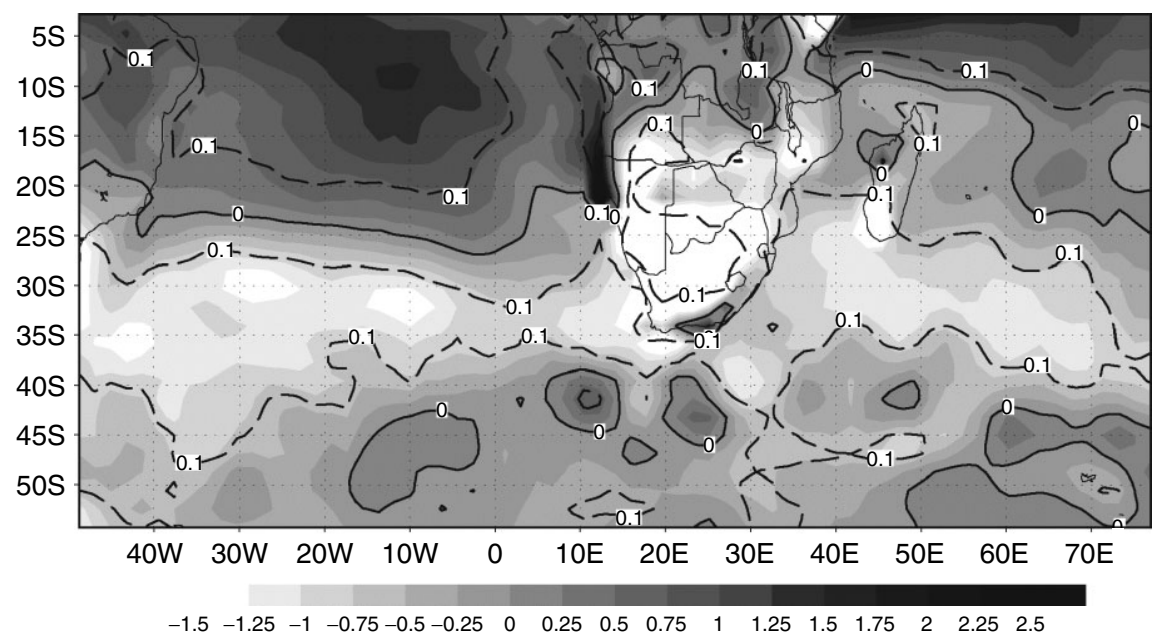

Figure 5. Surface-temperature composite mean (pos-neg amplitudes) from EOF 1 at $2.5^{\circ}$ spatial resolution. Temperature in ${ }^{\circ} \mathrm{C}$. Solid line $=$ zero contour, dashed line $=0.1$ significance level.

dry Mozambique Channel, both of which are statistically significant at the $90 \%$ level.

The geopotential height composite associated with the dates of extreme rainfall displays a clear divide of high pressure to the far east over Madagascar and low pressure over eastern and central southern Africa (Figure 8). In the surface-temperature composite corresponding to extreme days from this EOF, Figure 9, there is a region of cold (warm) anomalies in the South Atlantic (southern Indian Ocean), but the magnitudes of the temperature anomalies are very weak and spatially limited, despite being statistically significant. More importantly, however, is the extensive region of statistically significant warm anomalies over southeast Africa, reaching a $2.5^{\circ} \mathrm{C}$ anomaly at the maximum.

These diagonal bands of loadings and associated extreme rainfall may relate to variability caused by the
TTT feature discussed above, but with this feature shifted to the east compared to the leading EOF. In the second EOF, surface-temperature anomalies throughout the oceans are neither strong nor spatially extensive; however, the warm anomalies over eastern southern Africa suggest a heat-low that is further implied by the pressure composites. This heat-low may be responsible for anchoring the subtropical component of the TTT to the east, extending down into the southwest Indian Ocean, and resulting in higher rainfall over central and eastern southern Africa.

4.1.3. EOF 3. The third most dominant pattern of rainfall variability is indicative of a North-South divide, with the gradient lying at approximately $18^{\circ} \mathrm{S}$ (Figure 10). In this third EOF the negative loadings are centred over the southern half of the Democratic Republic of Congo 
(hereafter DRC), whereas the positive loadings are to the southeast. These positive loadings are now centred over the southwest Indian Ocean below the Mozambique Channel and, to some extent, are still distributed into the diagonal pattern indicative of the TTT features seen in the second EOF. However this diagonal band is now less spatially coherent and, combined with the fact that there are two clear regions of opposite rainfall variability to the north and south of southern Africa, it is argued that a North-South pattern is emerging from this EOF.

The precipitation composite of extreme amplitudes from this EOF is again similar to the $\mathrm{N}-\mathrm{S}$ pattern of rainfall variability identified from the third EOF, with statistically significant higher rainfall to the south compared to drier regions to the north (Figure 11). There are some differences between the two plots, such as there being two separate regions of high rainfall apparent in the composite, over the Mozambique Channel and Zimbabwe, whereas the EOF shows only one region of positive loadings centred to the south of Madagascar (Figures 10 and 11, respectively). The surfacetemperature structures corresponding to extremes from the third EOF are again different, with a dominance of anomalously warm water now apparent (Figure 12) in the southern Indian Ocean, where anomalies reach approximately $1.5^{\circ} \mathrm{C}$ and are statistically significant at both the $90 \%$ and $95 \%$ (not shown) levels.

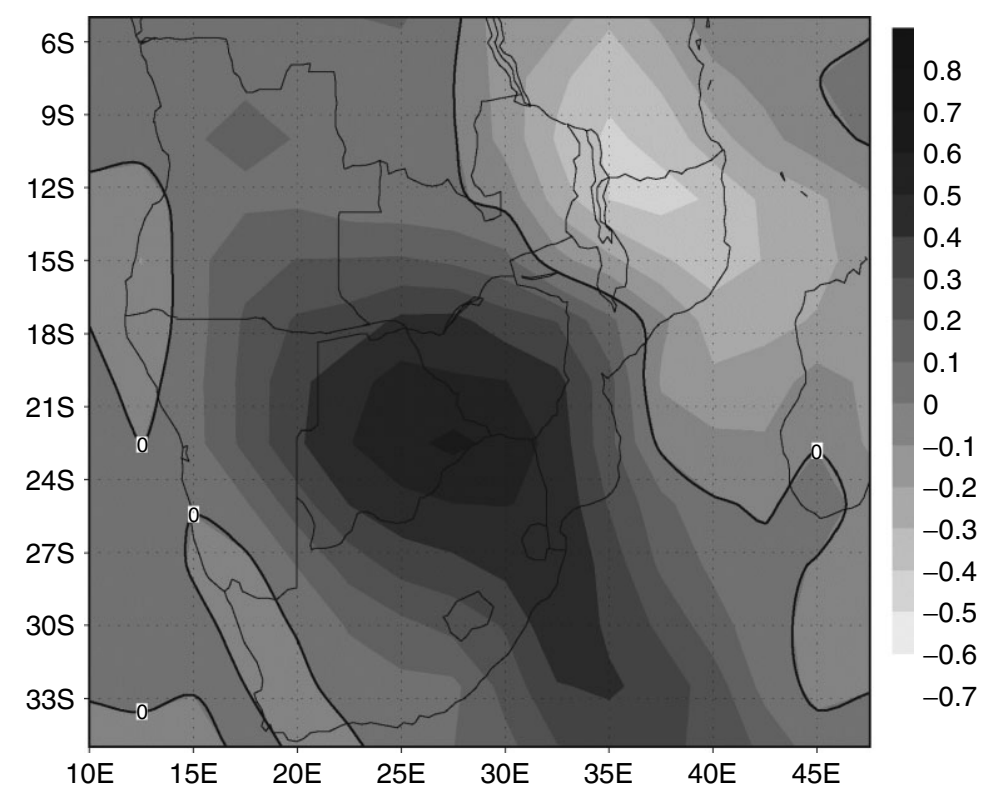

Figure 6. Spatial pattern of amplitudes from EOF 2 at $2.5^{\circ}$ spatial resolution, showing Nov-Apr rainfall variability. Solid line $=$ zero contour.

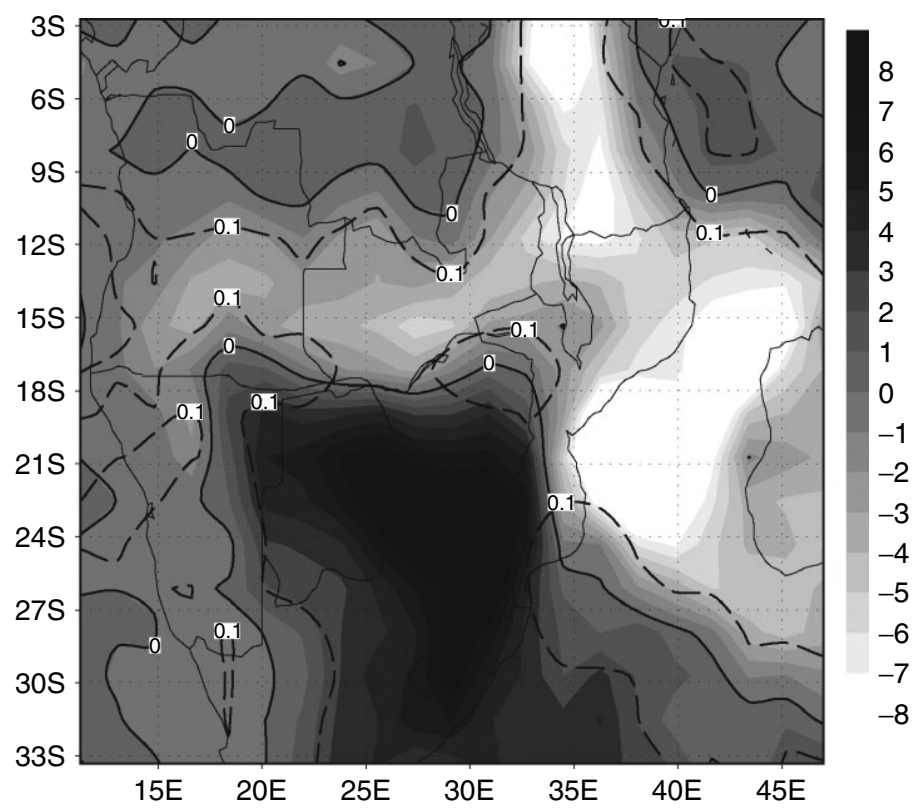

Figure 7. Surface precipitation composite mean (pos-neg amplitudes) from EOF 2 at $2.5^{\circ}$ spatial resolution. Precipitation in $\mathrm{mm}^{\mathrm{day}}{ }^{-1}$. Solid line $=$ zero contour, dashed line $=0.1$ significance level. 


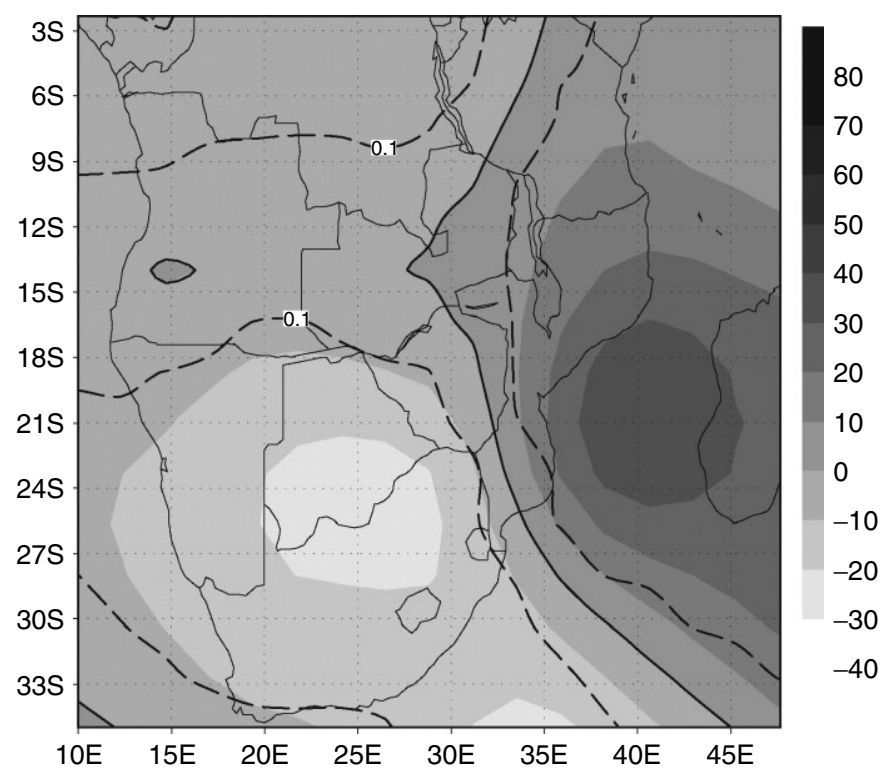

Figure $8.850 \mathrm{mb}$ geopotential height composite mean (pos-neg amplitudes) from EOF 2 at $2.5^{\circ}$ spatial resolution. Height in metres. Solid line $=$ zero contour, dashed line $=0.1$ significance level.

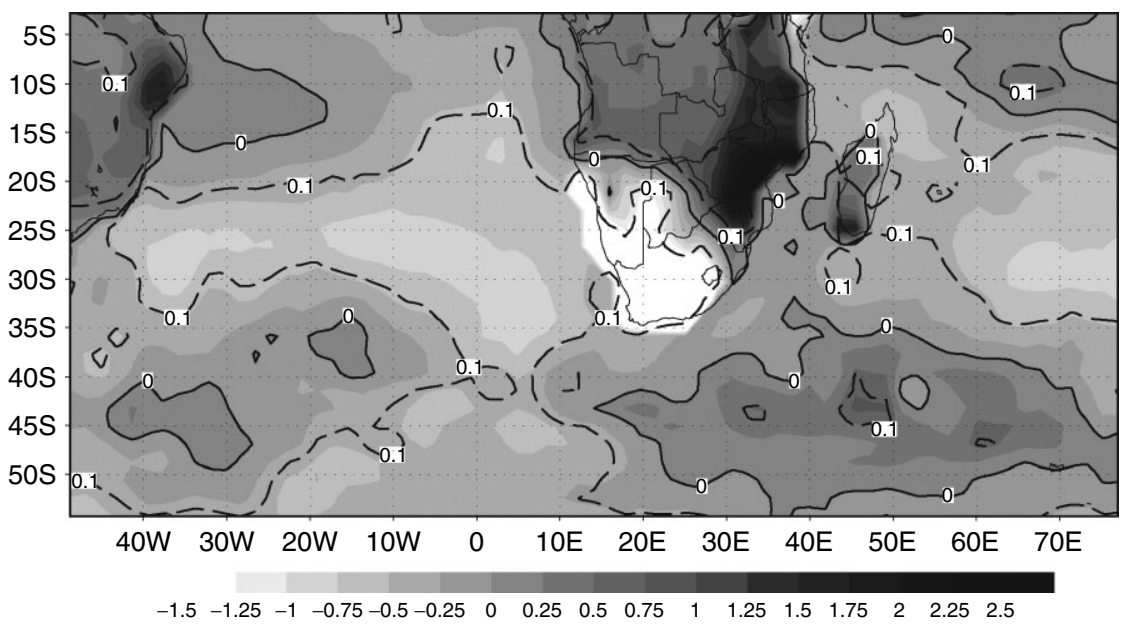

Figure 9. Surface-temperature composite mean (pos-neg amplitudes) from EOF 2 at $2.5^{\circ}$ spatial resolution. Temperature in ${ }^{\circ} \mathrm{C}$. Solid line $=$ zero contour, dashed line $=0.1$ significance level.

This EOF shows a pattern of lower rainfall variability to the north of the subcontinent compared to more variability in the southern countries. The extreme rainfall associated with this EOF may, therefore, relate to the rainfall gradient between the ITCZ and subtropics. The fact that the southern and eastern countries of southern Africa experience high rainfall in this EOF suggests that the TTT is again located to the east, the high latitude component of which may be anchored in this location by the region of warm anomalies in the southern Indian Ocean.

\section{COMPARISON OF VARIABILITY AND ASSOCIATIONS AT LOW AND HIGH RESOLUTION}

\subsection{Patterns of variability at $1^{\circ}$ spatial resolution, extreme days and associations}

Having identified the patterns of variability and associated atmospheric and oceanic circulation structures, the following section examines the effect of changing resolution on identifying surface-temperature anomalies connected to extreme days within this pattern.

5.1.1. EOF 1. The precipitation composite of extreme days with the amplitudes from the leading EOF at high resolution differs from the lower resolution composite in a number of regions. In Figure 13, it can be seen that the largest positive differences are coincident with the regions of higher rainfall, such as over Botswana and northern Angola. This suggests an extension of the TTT features over central southern Africa, relative to the lowresolution composites.

The surface-temperature composite associated with the extreme days from the first EOF also shows a clear difference between the two resolutions (Figure 14) for both the statistically significant, stronger warm and cold anomalies for the analysis at the higher resolution. The region of warmest water in the central South 


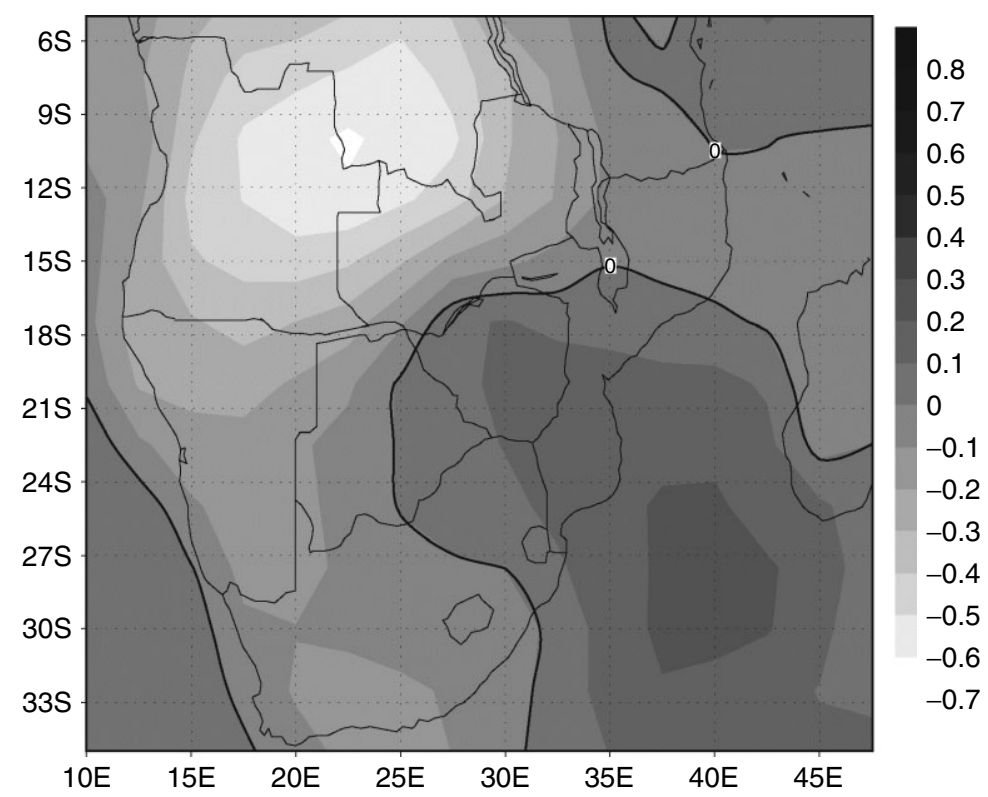

Figure 10. Spatial pattern of amplitudes from EOF 3 at $2.5^{\circ}$ spatial resolution, showing Nov-Apr rainfall variability. Solid line $=$ zero contour.

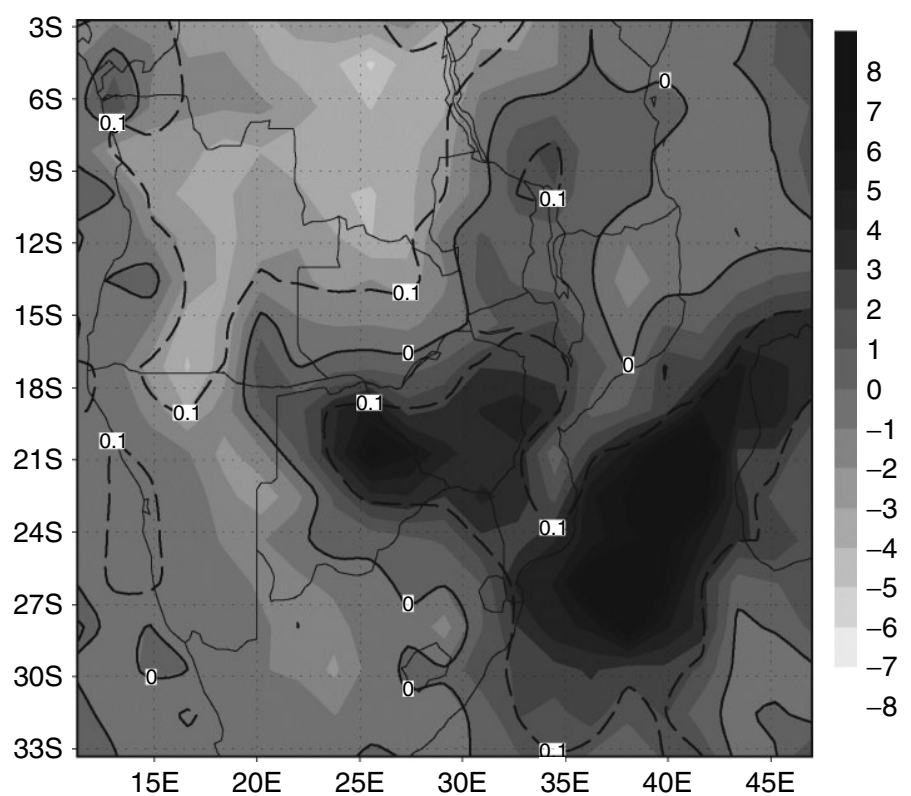

Figure 11. Surface precipitation composite mean (pos-neg amplitudes) from EOF 3 at $2.5^{\circ}$ spatial resolution. Precipitation in $\mathrm{mm}$ day ${ }^{-1}$. Solid line $=$ zero contour, dashed line $=0.1$ significance level.

Atlantic, centred around $10-20^{\circ} \mathrm{W}$, is now much larger in extent than it was at low resolution (Figure 5). The surface-temperature difference plot between the analyses at the two resolutions (Figure 15) shows a $0.4{ }^{\circ} \mathrm{C}$ difference, implying that the high-resolution composite shows a $16 \%$ increase in temperature anomaly for this region compared to the low-resolution composite. Further, the cooler temperatures are now shown to be much colder by up to $1{ }^{\circ} \mathrm{C}$, particularly, in the extreme southwestern Atlantic and over the subcontinent.

5.1.2. EOF 2. When the extreme rainfall and circulation structures corresponding to the second EOF are examined, the differences between the two resolutions are very few. For example, the precipitation-difference plot shows very little deviation from zero throughout most of the subcontinent (Figure 16). This is also true for the near-surface geopotential height differences (not shown), where most of the subcontinent displays no difference between the high- and low-resolution composites. The surface-temperature difference plot also shows little deviation from zero throughout the Atlantic and Indian Ocean (not shown), and so it may be concluded that, for this EOF, there is not much difference between using a high and low spatial resolution as a basis for investigating the oceanic associations with rainfall variability. 


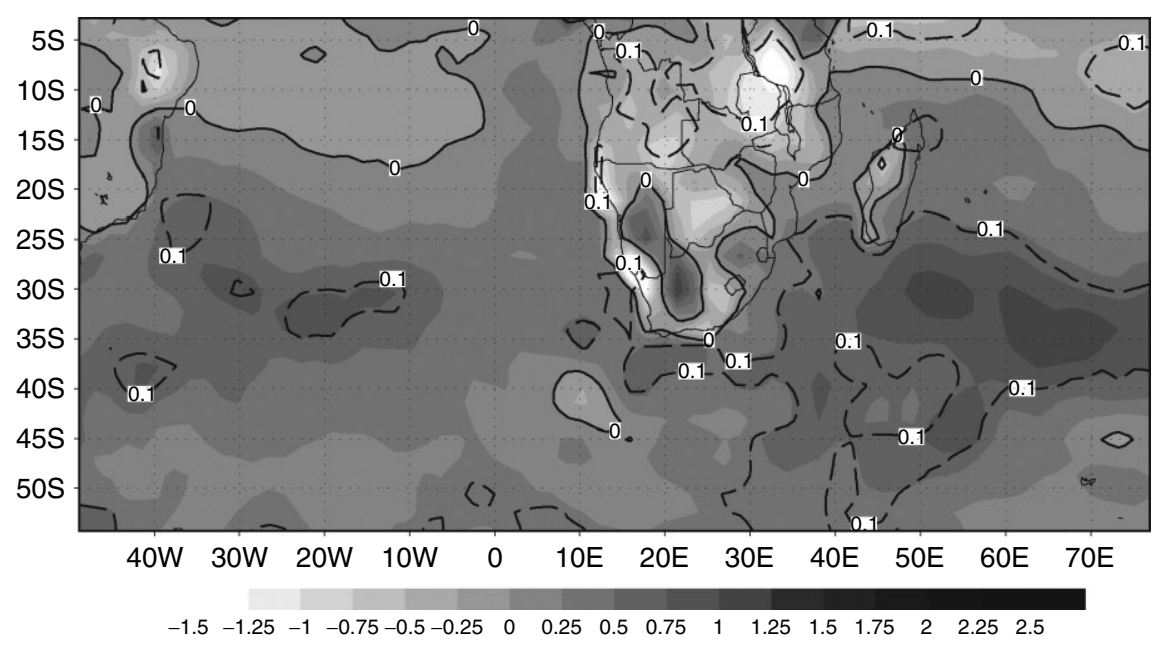

Figure 12. Surface-temperature composite mean (pos-neg amplitudes) from EOF 3 at $2.5^{\circ}$ spatial resolution. Temperature in ${ }^{\circ} \mathrm{C}$. Solid line $=$ zero contour, dashed line $=0.1$ significance level.

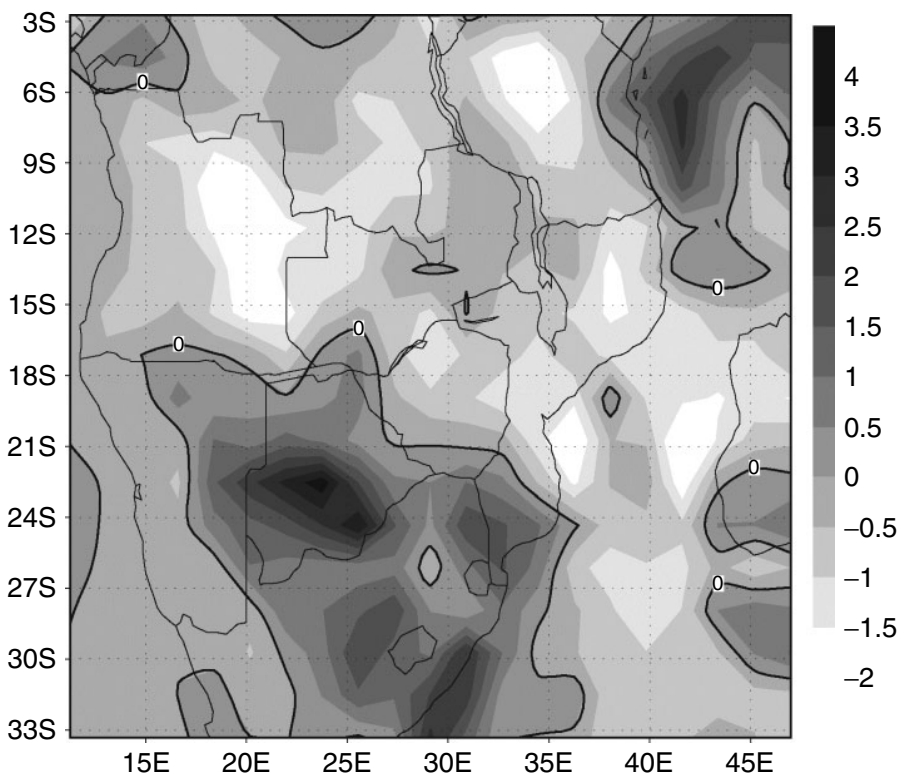

Figure 13. Surface precipitation differences from EOF 1 , at $1^{\circ}$ minus $2.5^{\circ}$ spatial resolution. Values in $\mathrm{mm} \mathrm{day}^{-1}$. Solid line $=$ zero contour.

This is consistent with the hypothesis that extreme rainfall is associated with a land-based driver rather than the Atlantic or Indian Ocean SST. Possible reasons for this lack of difference between resolutions are discussed in the following section.

5.1.3. EOF 3. Results very different from those of the first two EOFs are obtained on an examination of the extreme rainfall and circulation structures corresponding to the third EOF. Figure 17 shows the precipitationdifference plot for extreme days with the amplitudes from this EOF. The composite suggests that, for certain regions of rainfall, such as over Madagascar, the Mozambique Channel, and eastern South Africa, the low-resolution composite shows more rainfall than the high-resolution composite. Further, the surface-temperature composite shows that a higher resolution (Figure 18) yields weaker and more spatially limited statistically significant temperatures than the lower resolution (Figure 12). Consequently, for extreme events from the third EOF, it would appear that, in contrast to the leading EOF, a lower resolution shows an enhanced TTT located to the east and warmer Indian Ocean SST anomalies.

\subsection{Temporal analysis of amplitudes}

The differences between the resolutions can be seen clearly if the dates from the amplitudes of each EOF at the two resolutions are examined. Table II shows, for each EOF, the dates highlighted by each resolution that are not accounted for by the other resolution. So, using the first EOF as an example, the left-hand column shows the dates highlighted at high resolution that are not identified when using a low resolution, and vice versa for the right-hand column. The leading EOF shows 


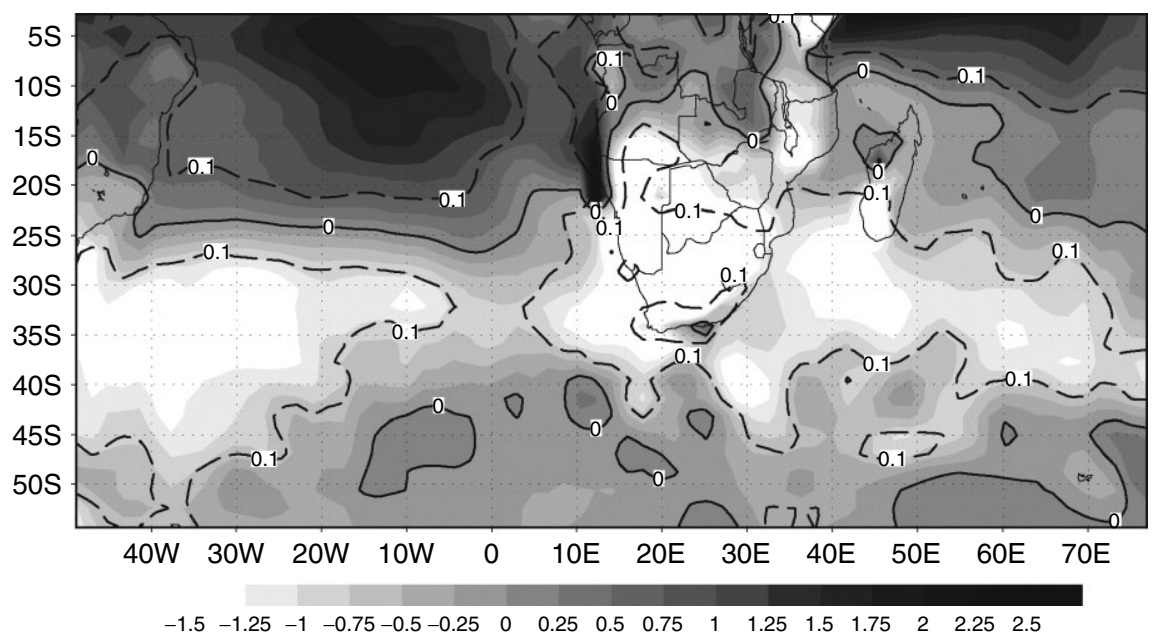

Figure 14. Surface-temperature composite mean (pos-neg amplitudes) from EOF 1 at $1^{\circ}$ spatial resolution. Temperature in ${ }^{\circ} \mathrm{C}$. Solid line $=$ zero contour, dashed line $=0.1$ significance level.

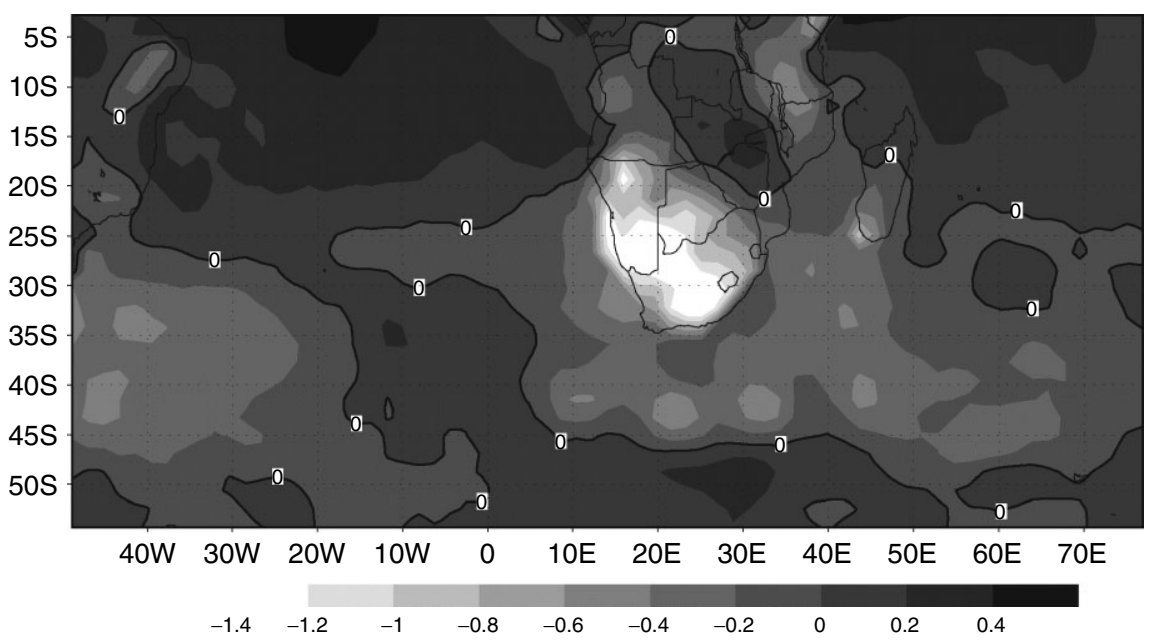

Figure 15. Surface-temperature differences from EOF 1, at $1^{\circ}$ minus $2.5^{\circ}$ spatial resolution. Values in $^{\circ} \mathrm{C}$. Solid line $=$ zero contour.

some difference between the resolutions with an almost equal number of different days, the second EOF shows little difference, having very few different days, and the third EOF shows a great deal of difference with more days being highlighted at low resolution, which are not identified at high resolution. Because of these differences, the analysis from the first EOF shows a better defined atmospheric and oceanic signal associated with extreme events and variability at high resolution, whereas analysis of the third EOF does not show this and instead shows a better defined signal associated with extreme events at low resolution.

It is also useful to consider briefly the temporal distribution of the loadings for each EOF. The first EOF shows several periods of prolonged positive loadings at both high and low resolution (more than 3 days), particularly at the end of the wet season in April 1998 and 1999. The negative loadings, suggesting low rainfall variability for this EOF, show numerous, but shorter (2 days), periods of loadings. This suggests that although dry periods occur relatively frequently in the leading EOF, they are not prolonged and therefore would not imply initiation of drought conditions. The second EOF, however, does show a prolonged period of negative loadings that lasts 5 (7) days at high (low) resolution during January 1993, suggesting that there was a prolonged period of low rainfall variability during this normally highly variable month. Finally, the third EOF is again similar to the first in terms of the temporal distribution of both positive and negative loadings at either resolution, in that periods of 2 or 3 days occur frequently but do not last.

\section{DISCUSSION AND CONCLUSIONS}

The work presented in this paper has attempted to identify the large-scale atmospheric and oceanic patterns that are associated with extremes of rainfall variability over southern Africa. A PCA has been performed on daily rainfall data at two spatial resolutions. Dates of extreme rainfall variability associated with the spatial patterns revealed from the PCA have then been used 


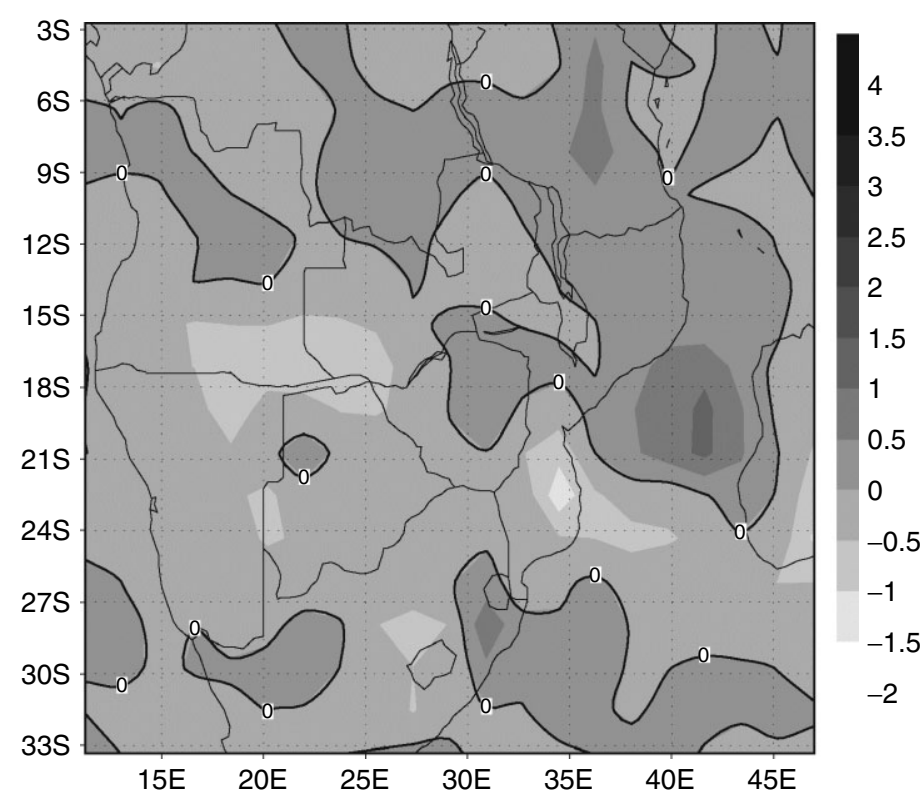

Figure 16. Surface precipitation differences from EOF 2, at $1^{\circ}$ minus $2.5^{\circ}$ spatial resolution. Values in $\mathrm{mm} \mathrm{day}^{-1}$. Solid line $=$ zero contour.

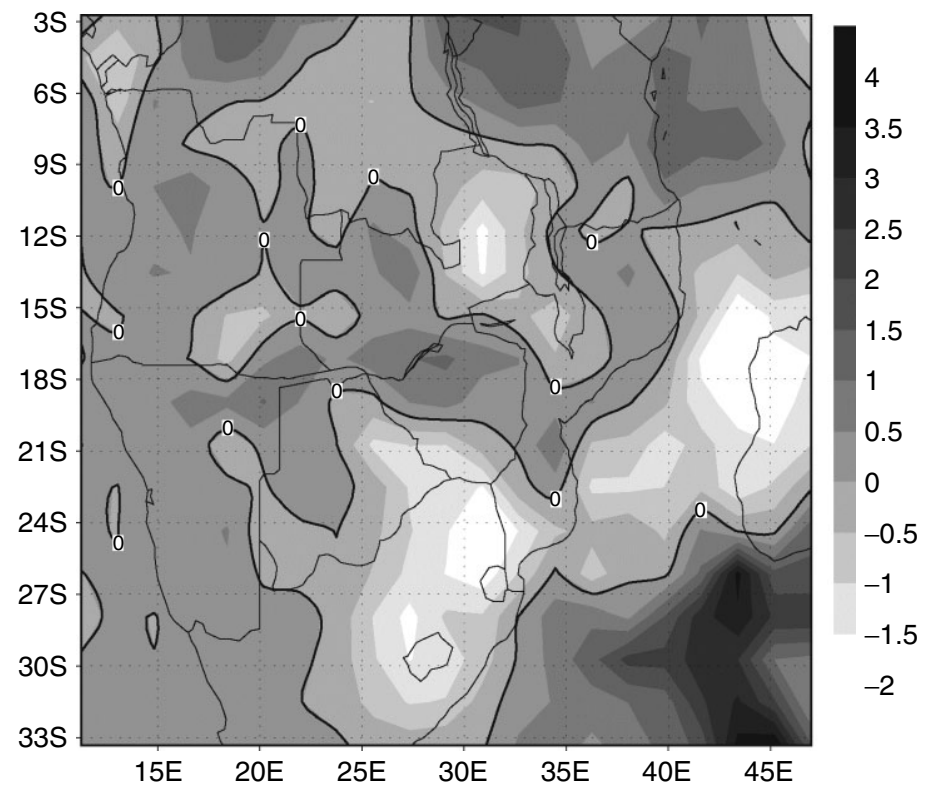

Figure 17. Surface precipitation differences from EOF 3, at $1^{\circ}$ minus $2.5^{\circ}$ spatial resolution. Values in $\mathrm{mm} \mathrm{day}^{-1}$. Solid line $=$ zero contour.

to composite climate parameters. Three dominant spatial patterns (EOFs) of rainfall variability have been identified: the first seems to be showing an East-West gradient over the subcontinental interior and the southeast Atlantic, possibly associated with an Atlantic El Niño pattern; the second appears to show two NW-SE diagonal bands and may therefore relate to TTTs; and the third seems to display a North-South gradient over tropical and subtropical southern Africa, which may relate to the rainfall gradient between the ITCZ and the drier subtropical region.

The results suggest that the extreme rainfall events from each set of daily amplitudes (from each EOF) are associated with a different location of the TTTs resulting from both local and remote atmospheric and oceanic processes. It would appear that extremes connected to the first EOF may be associated with a remote mechanism from the South Atlantic, whereby a region of warm oceanic surface-temperature anomalies have an indirect effect on rainfall variability by suppressing the Walker cell, enhancing a Hadley-style circulation and therefore the equatorial low, and consequently shifting the position of the TTTs towards the west. For extremes corresponding to the second EOF, the composites suggest that the position of the TTTs may result from a local, land-based mechanism related to a region of warm temperature anomalies over eastern southern Africa, rather than being associated with any oceanic temperature 


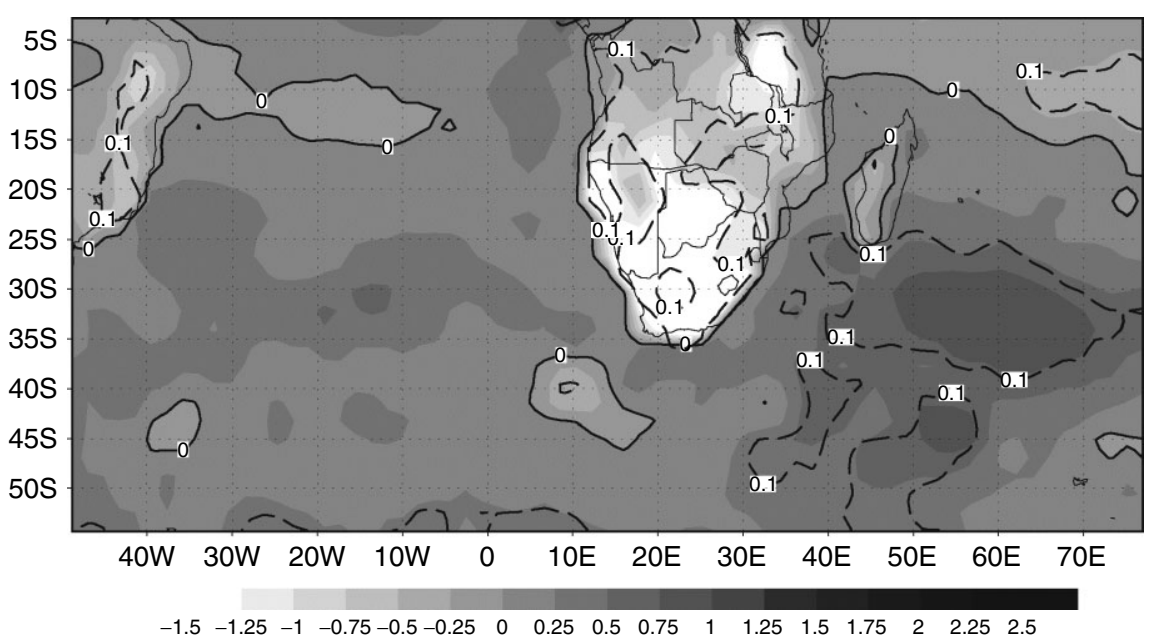

Figure 18. Surface-temperature composite mean (pos-neg amplitudes) from EOF 3 at $1^{\circ}$ spatial resolution. Temperature in ${ }^{\circ} \mathrm{C}$. Solid line $=$ zero contour, dashed line $=0.1$ significance level.

Table II. Different dates obtained with the amplitudes from each EOF, for the two resolutions. Dates are those from high $\left(1^{\circ}\right)$ resolution, which are not highlighted at low $\left(2.5^{\circ}\right)$ resolution, and vice versa. Unshaded $=$ positive amplitudes, shaded $=$ negative amplitudes.

\begin{tabular}{|c|c|c|c|c|c|}
\hline \multicolumn{2}{|c|}{ EOF 1} & \multicolumn{2}{|c|}{ EOF 2} & \multicolumn{2}{|c|}{ EOF 3} \\
\hline $1^{\circ}$ & $2.5^{\circ}$ & $1^{\circ}$ & $2.5^{\circ}$ & $1^{\circ}$ & $2.5^{\circ}$ \\
\hline 28/04/1995 & $25 / 01 / 1994$ & 03/03/1994 & $18 / 01 / 1993$ & $12 / 01 / 1993$ & 02/01/1994 \\
\hline 29/04/1995 & $02 / 04 / 1995$ & $30 / 11 / 1995$ & 04/03/1994 & $29 / 03 / 1993$ & 03/03/1994 \\
\hline 23/04/1997 & $01 / 02 / 1996$ & $18 / 11 / 1996$ & & $29 / 12 / 1993$ & $04 / 12 / 1994$ \\
\hline 17/04/1998 & $30 / 01 / 1998$ & 02/01/1997 & & 20/01/1994 & $27 / 02 / 1996$ \\
\hline 30/04/1998 & $02 / 04 / 2000$ & 02/01/1999 & & $02 / 02 / 1995$ & $13 / 03 / 1996$ \\
\hline 27/04/1999 & $27 / 02 / 2002$ & $11 / 12 / 2001$ & & $01 / 12 / 1995$ & $19 / 03 / 1997$ \\
\hline \multirow[t]{14}{*}{ 28/04/1999 } & & & & 08/03/1996 & 26/03/1997 \\
\hline & & & & $18 / 02 / 1999$ & $25 / 03 / 1998$ \\
\hline & & & & $30 / 04 / 1999$ & 09/04/1998 \\
\hline & & & & $19 / 12 / 2000$ & $04 / 12 / 1998$ \\
\hline & & & & $26 / 02 / 2001$ & 07/03/1999 \\
\hline & & & & $06 / 12 / 2001$ & $19 / 03 / 1999$ \\
\hline & & & & $11 / 12 / 2001$ & $29 / 11 / 1999$ \\
\hline & & & & $17 / 12 / 2001$ & $11 / 12 / 1999$ \\
\hline & & & & $30 / 12 / 2001$ & $12 / 12 / 1999$ \\
\hline & & & & & $24 / 03 / 2000$ \\
\hline & & & & & $16 / 11 / 2000$ \\
\hline & & & & & $17 / 01 / 2001$ \\
\hline & & & & & $30 / 03 / 2001$ \\
\hline & & & & & $06 / 04 / 2001$ \\
\hline
\end{tabular}

anomalies. This region of warm subtropical anomalies over the land may act to anchor the TTT to the centre of southern Africa. Finally, the results suggest that extremes connected to the third EOF may be associated with a remote oceanic mechanism from the southern Indian Ocean, whereby a region of warm surface-temperature anomalies is responsible for anchoring the high latitude part of the TTT to the extreme east of the region.

The results also suggest that, for extreme rainfall events associated with the most common spatial pattern of rainfall variability, the first EOF, using a higher resolution of rainfall detail provides a more coherent signal than using a lower resolution. In this instance the increased coherence is shown by a stronger (in magnitude) and clearer (in terms of spatial extent) coincident surface-temperature anomaly in the central South Atlantic. As discussed above, this region of warm anomalies is associated with the pattern of variability that may be related to an Atlantic El Niño pattern. Extreme rainfall variability associated with the second EOF shows little difference between the resolutions, with the number of different dates comprising only approximately $4 \%$ of the total, hence the similarity in atmospheric and oceanic signal. Finally, extreme rainfall variability associated 
with the third EOF shows a lot of difference between the resolutions, but shows opposite results to that from the first EOF in that a stronger, in magnitude, and spatially clearer atmospheric and oceanic signal is obtained when using a lower resolution.

It should be noted that significant testing between the two resolutions reveals no statistically significant differences in surface-temperature patterns. This is to be expected as both resolutions use the same rainfall data; it is not argued here that data at a higher spatial resolution provides a different signal, rather that it provides an atmospheric and oceanic signal that is both stronger in magnitude and clearer to identify spatially. This finding is therefore subtler, being related to the scales of interaction between atmospheric and oceanic structures and rainfall, in the context of using SST anomalies for climate modelling purposes.

There are several possible explanations for these results. Firstly, rainfall extremes can be divided into two components: those arranged in large-scale patterns controlled by large-scale atmospheric and oceanic mechanisms, and those arranged randomly by localised convective activity. Consequently, the inconsistency between the impact of spatial resolution on extreme days from the first and third EOFs may be explained by the ratio between the large-scale controlled extreme variability, the 'signal', and the randomly arranged extreme variability, the 'noise', in each set of amplitudes. As the EOF progresses in number and the amount of rainfall variance explained by the large-scale pattern decreases, the influence of random variability increases. Further, as the spatial resolution becomes higher, the variability increases, which means that the number of random events identified again increases. Consequently, with the amplitudes from the third EOF, which are naturally 'noisy' as the amount of variance accounted for has decreased from $9.60 \%$ for the first EOF to $4.45 \%$ here (from 7.58 to $3.26 \%$ ) at low (high) resolution, the level of averaging required to produce the lower resolution pattern may be smoothing out some of the random variability while retaining the larger-scale signal. Conversely, with the amplitudes from the first EOF the level of noise is naturally lower because the EOF accounts for the most variance and therefore focuses more on the large-scale patterns of variability rather than random events. A higher resolution can therefore be more effective at identifying extreme rainfall variability because the large-scale related variability does not get as contaminated by noise.

Secondly, it is possible that other methods of analysing the data at two spatial resolutions and extracting extreme days are preferable to carrying out a PCA. Defining an extreme day as being above a certain threshold of the mean climatological total or counting the number of days with extreme pixels are two alternative methods that may yield different results. Thirdly, and further to the second reason, this inconsistency between extreme variability from the EOFs might be explained by the possibility that the extremes may not be arranged in the same pattern as the modes revealed by the PCA.
While the assumption that extremes are arranged similar to the common patterns appears to be supported by the composites from the amplitudes of the first EOF, there are differences between the composites and the spatial patterns of variability for the second and third EOFs, which may suggest that extreme rainfall events are arranged differently to the common patterns of variability for these spatial patterns.

Lastly, this work has only examined surface-temperature anomalies that are coincident with the rainfall extremes. Consequently, the inconsistency between the amplitudes of the EOFs at different resolutions may be due to cotemporal surface temperatures being less related to extreme rainfall variability highlighted by the less dominant second and third EOFs. These less common patterns of rainfall variability and corresponding extremes may be more associated with the surface-temperature structures prior to the extreme rainfall events, such as those anomalies occurring during the previous dry season. A full investigation into the lags and leads of surface temperature in relation to extreme rainfall events is beyond the scope of this paper, but warrants further work.

The primary goals of this paper were to identify potential atmospheric and oceanic associations with southern African daily rainfall extremes, and to investigate the effect of spatial resolution in highlighting these associations. The aim of these goals is to obtain coherent patterns of surface-temperature anomalies that can be used as a basis for climate modelling. The results suggest that when using extreme dates obtained with the amplitudes from the leading mode of variability, the use of a higher resolution is preferred. Using this EOF, the mechanisms associated with extreme rainfall variability, such as pressure and surface temperature, are more coherent when viewed using a higher resolution PCA. This extra detail would be crucial when choosing regions of SST, e.g. to force global or regional climate models, as it would reduce the potential to ignore certain centres of action. For example, if the surface-temperature composite at $2.5^{\circ}$ resolution (Figure 5) was the basis for choosing anomalous SST regions to force a GCM, selecting a clear region would be difficult as there is no strong signal. The region of warm anomalies in the South Atlantic might be chosen, but the temperatures are not high, reaching only $1.5^{\circ} \mathrm{C}$ at their peak. However, the surface-temperature composite at $1^{\circ}$ resolution (Figure 14) shows a different picture. Here, the same region in the South Atlantic is much warmer and covers a larger area, and so would be a good area to place warm SST anomalies in a model. The large region of cold temperature anomalies south of Brazil would also be a potential choice for forcing a model with cold SST anomalies.

Thus, from a modelling perspective, investigating the associations with rainfall extremes contained within the most common pattern of variability at higher resolution yields more useful information than using a lower spatial scale. When using rainfall extremes from less dominant 
patterns of rainfall variability, a lower spatial resolution is preferable. The issue of spatial resolution in obtaining a coherent atmospheric and oceanic signal is therefore an important one for future climate modelling work.

\section{ACKNOWLEDGEMENTS}

The images were provided by the NOAA-CIRES Climate Diagnostics Center, Boulder, Colorado, from their website at http://www.cdc.noaa.gov/. We acknowledge computing support from the Sussex High Performance Computing Initiative.

\section{REFERENCES}

Arkin P, Meisner B. 1987. The relationship between large-scale convective rainfall and cold cloud over the western-hemisphere during 1982-84. Monthly Weather Review 115(1): 51-74.

Biasutti M, Battisti D, Sarachik E. 2004. Mechanisms controlling the annual cycle of precipitation in the tropical Atlantic sector in an atmospheric GCM. Climate Dynamics 23(7-8): 717-726.

Binet D, Gobert B, Maloueki L. 2001. El Niño-like warm events in the Eastern Atlantic $\left(6^{\circ} \mathrm{N}, 20^{\circ} \mathrm{S}\right)$ and fish availability from Congo to Angola (1964-1999). Aquatic Living Resources 14: 99-113.

Buell C. 1975. The topography of the empirical orthogonal functions. Fourth Conference on Probability and Statistics in Atmospheric Sciences. American Meteorological Society: Tallahassee, FL.

D'Abreton P, Lindesay J. 1993. Water vapour transport over southern Africa during wet and dry early and late summer months. International Journal of Climatology 13: 151-170.

Desanker P, Magadza C. 2001. Chapter 10: Africa. In Climate Change 2001: Impacts, Adaptation and Vulnerability. Contribution of Working Group II to the Third Assessment Report of the Intergovernmental Panel on Climate Change, McCarthy $\mathrm{J}$, Canziani O, Leary N, Dokken D, White K (eds). Cambridge University Press: Cambridge; 1032.

Fauchereau N, Trzaska S, Rouault M, Richard Y. 2003. Rainfall variability and changes in southern Africa during the 20th century in the global warming context. Natural Hazards 29(2): 139-154.

Goddard L, Graham N. 1999. Importance of the Indian Ocean for simulating rainfall anomalies over eastern and southern Africa. Journal of Geophysical Research 104(D16): 19009-19116.

Harrison M. 1984. A generalised classification of South African summer rain-bearing synoptic systems. Journal of Climatology 4 $547-560$.

Hirst A, Hastenrath S. 1983. Atmosphere-ocean mechanisms of climate anomalies in the Angola-tropical Atlantic sector. Journal of Physical Oceanography 13: 1146-1157.

Hudson D, Jones R. 2002. Simulations of present-day and future climate over southern Africa using HadAM3H. Hadley Centre Technical Note 38, Met. office, Hadley Centre for Climate Prediction and Research, Bracknell: 37.

Janowiak J. 1988. The averaging region is based on the rotated principal component analysis of average June through September African rainfall. Journal of Climate 1: 240-255.

Joliffe I. 1987. Rotation of principal components: some comments. Journal of Climatology 7: 507-510.

Jury M. 1994. A thermal front within the marine atmospheric boundary layer over the Agulhas Current south of Africa: composite aircraft observations. Journal of Geophysical Research 99: 3297-3304.

Jury M, Pathack B. 1993. Composite climatic patterns associated with extreme modes of summer rainfall over southern Africa: 1975-1984. Theoretical and Applied Climatology 47: 137-145.

Jury M, Valentine H, Lutjeharms J. 1993. Influence of the Agulhas Current on summer rainfall along the southeast coast of South Africa. Journal of Applied Meteorology 32: 11282-11287.

Kalnay E, Kanamitsu M, Kistler R, Collins W, Deaven D, Gandin L, Iredell M, Saha S, White G, Woollen J, Zhu Y, Chelliah M, Ebisuzaki W, Higgins W, Janowiak J, Mo K, Ropelewski C, Wang J, Leetmaa A, Reynolds R, Jenne R, Joseph D. 1996. The NCEP/NCAR 40-year reanalysis project. Bulletin of the American Meteorological Society 77(3): 437-471.
Layberry R, Kniveton D, Todd M, Kidd C, Bellerby T. 2006. Daily precipitation over southern Africa: a new resource for climate studies. Journal of Hydrometeorology 7(1): 149-159.

Li S, Robinson W, Peng S. 2003. Influence of the north Atlantic SST tripole on northwest African rainfall. Journal of Geophysical Research-Atmospheres 108(D19): 16.

Lindesay J. 1988. South African rainfall, the Southern Oscillation, and a Southern Hemisphere annual cycle. Journal of Climatology 8: 17-30.

Mason S. 1995. Sea surface temperature - South Africa rainfall associations, 1910-1989. International Journal of Climatology 15: 119-135.

Mason S, Tyson P. 1992. The modulation of sea surface temperature and rainfall associations over southern Africa with solar activity and the Quasi-Biennial Oscillation. Journal of Geophysical Research 97(D5): 5847-5856.

McGuffie K, Henderson-Sellers A, Holbrook N, Kothavala Z, Balachova O, Hoekstra J. 1999. Assessing simulations of daily temperature and precipitation variability with global climate models for present and enhanced greenhouse climates. International Journal of Climatology 19(1): 1-26.

Merle J. 1980. Annual and interannual variability of temperature in the eastern equatorial Atlantic Ocean - Hypothesis of an Atlantic El Niño. Oceanologica Acta 3(2): 209-220.

Mey R, Walker N, Jury M. 1990. Surface heat fluxes and marine boundary layer modification in the Agulhas retroflection region. Journal of Geophysical Research 95: 15997-16015.

Misra V. 2003. The influence of pacific SST variability on the precipitation over southern Africa. Journal of Climate 16(14): 2408-2418.

Moron V, Bigot S, Roucou P. 1995. Rainfall variability in subequatorial America and Africa and relationships with the main sea-surface temperature models 1951-1990. International Journal of Climatology 15: 1297-1322.

Moron V, Philippon N, Fontaine B. 2003. Skill of Sahel rainfall variability in four atmospheric GCMs forced by prescribed SST. Geophysical Research Letters 30(23): 4.

Mulenga H. 1998. Southern African climatic anomalies, summer rainfall and the Angola low, $\mathrm{PhD}$ thesis, University of Cape Town, 261.

Nicholson S. 1986. The nature of rainfall variability in Africa south of the equator. Journal of Climatology 6: 515-530.

North G, Bell T, Cahalan R, Moeng F. 1982. Sampling errors in the estimation of empirical orthogonal functions. Monthly Weather Review 110: 699-706.

Paeth H, Friederichs P. 2004. Seasonality and timescales in the relationship between global SST and African rainfall. Climate Dynamics 23(7-8): 815-837.

Rautenbach C, Smith I. 2001. Teleconnections between global sea surface temperatures and the interannual variability of observed and model simulated rainfall over southern Africa. Journal of Hydrology 254(1-4): $1-15$.

Reason C. 1998. Warm and cold events in the southeast Atlantic/southwest Indian Ocean region and potential impacts on circulation and rainfall over southern Africa. Meteorology and Atmospheric Physics 69: 49-65.

Reason C. 2002. Sensitivity of the southern African circulation to dipole sea surface temperature patterns in the south Indian Ocean. International Journal of Climatology 22(4): 377-393.

Reason C, Godfred-Spenning C. 1998a. SST variability in the South Indian Ocean and associated circulation and rainfall patterns over southern Africa. Meteorology and Atmospheric Physics 66: 243-258.

Reason C, Lutjeharms J. 1998b. Variability of the South Indian Ocean and implications for southern African rainfall. South African Journal of Science 94: 115-122.

Reason C, Keibel A. 2004. Tropical Cyclone Eline and its unusual penetration and impacts over the southern African mainland. Weather and Forecasting 19(5): 789-805.

Reason C, Jagadheesha D. 2005a. Relationships between South Atlantic SST variability and atmospheric circulation over the South African region during austral winter. Journal of Climate 18(16): 3339-3355.

Reason C, Hachigonta S, Phaladi R. 2005b. Interannual variability in rainy season characteristics over the Limpopo region of southern Africa. International Journal of Climatology 25(14): 1835-1853.

Richman M. 1986. Rotation of principal components. International Journal of Climatology 6: 293-335. 
Rocha A, Simmonds I. 1997. Interannual variability of south-eastern African summer rainfall. Part 1: relationships with air-sea interaction processes. International Journal of Climatology 17: 235-265.

Ropelewski C, Halpert M. 1987. Global and regional scale precipitation patterns associated with the El Niño/Southern Oscillation. Monthly Weather Review 115: 1606-1626.

Shinoda M, Kawamura R. 1996. Relationships between rainfall over semi-arid Southern Africa, geopotential heights, and sea surface temperatures. Journal of the Meteorological Society of Japan 74(1): $21-36$.

Suzuki R, Behera S, Iizuka S, Yamagata T. 2004. Indian Ocean subtropical dipole simulated using a coupled general circulation model. Journal of Geophysical Research-Oceans 109(C9), C09001: $1-18$.

Tegart W, Sheldon G, Griffiths D. 1990. Impacts Assessment of Climate Change. Report by Working Group II of the Intergovernmental Panel on Climate Change. Australian Government Printing Service: Canberra.

Todd M, Washington R, Palmer P. 2004. Water vapour transport associated with tropical-temperate trough systems over Southern
Africa and the Southwest Indian Ocean. International Journal of Climatology 24: 555-568.

Todd M, Kidd C, Kniveton D, Bellerby T. 2001. A combined satellite infrared and passive microwave technique for estimation of small scale rainfall over the global tropics and subtropics. Journal of Atmospheric and Oceanic Technology 18: 742-755.

Tyson P. 1986. Climate Change and Variability in Southern Africa. Oxford University Press: Cape Town; 220.

Tyson P, Preston-Whyte R. 2000. The Weather and Climate of Southern Africa. Oxford University Press: Cape Town; 384.

Walker N. 1990. Links between South African summer rainfall and temperature variability of the Agulhas and Benguela Current systems. Journal of Geophysical Research 95: 3297-3319.

Washington R, Todd M. 1999. Tropical-temperate links in southern Africa and southwest Indian Ocean satellite-derived daily rainfall. International Journal of Climatology 19: 1601-1616.

White D, Richman M, Yarnal B. 1991. Climate regionalisation and rotation of principal components. International Journal of Climatology 11: 1-25. 